\title{
Impact of Job Crafting on Quality of Care: The Moderating Effect of Commitment
}

\author{
Marina Romeo1, Montserrat Yepes-Baldó1, Kristina Westerberg², Maria Nordin² \\ ${ }^{1}$ Universitat de Barcelona, Barcelona, Spain \\ ${ }^{2}$ Umeå Universitet, Umeå, Sweden \\ Email: mromeo@ub.edu
}

How to cite this paper: Romeo, M. Yepes-Baldó, M., Westerberg, K., \& Nordin, M. (2018). Impact of Job Crafting on Quality of Care: The Moderating Effect of Commitment. Psychology, 9, 2649-2661. https://doi.org/10.4236/psych.2018.912151

Received: September 6, 2018

Accepted: November 17, 2018

Published: November 20, 2018

Copyright (c) 2018 by authors and Scientific Research Publishing Inc. This work is licensed under the Creative Commons Attribution International License (CC BY 4.0).

http://creativecommons.org/licenses/by/4.0/

(c) (i) Open Access

\begin{abstract}
The present study is part of a broader research project aimed at the analysis of the job environment of eldercare and nursing homes employees. In this context, the aim of this research is to analyze the direct effect of job crafting, specifically, task, relational and cognitive crafting, on quality of care, and the moderator effect of commitment on these relationships. A correlational cross-sectional design was used. A non-probabilistic accidental sample of 530 eldercare and nursing home employees was recruited. Standardized instruments were used to assess employees' job crafting, quality of care and commitment. Regression analyses with PROCESS were used to test the moderated model. Results showed a moderated effect of exchange, values, and affective commitment on the relationship between cognitive job crafting and quality of care, but not on the relationship of task and relational job crafting and quality of care. This study highlights the importance of nurses' job crafting activities for quality of care. Quality of care depends on cognitive job crafting among nurses with high levels of organizational commitment. Those employees with high levels of need commitment perceived low levels of quality of care, independently of their job crafting.
\end{abstract}

\section{Keywords}

Job Crafting, Organizational Commitment, Quality of Care, Eldercare, Nursing Homes Employees

\section{Introduction}

The European demographic development shows an aging population, and this means a growing number of older people in need of care. As stated at the European Summit on Innovation for Active and Healthy Ageing (5 - 8 December 
2016) the rising demand for health, social and informal care services due to the ageing population and a growing burden of chronic diseases, is estimated to increase health and care expenditure on average by $1 \%-2 \%$ of GDP until 2060, at a time of constrained public resources for health and social care (European Commission, 2017: p. 4).

Nevertheless, during the financial crisis starting in 2008, the working conditions of health workers have worsened: frozen wages, reduction in personnel, work overload, increased staff turnover, decreased status, and reduced work expectations, compromising the quality of care for patients (Van Bogaert, Kowalski, Weeks, \& Clarke, 2013). In these sense, Shin and Lee (2016) consider it critical to "try to enhance nurses' psychosocial work environment and attend to present and potential problems within their work environment” (p. 935).

Employees' job crafting activities and commitment contribute to employees' performance, especially the quality of care they give to patients. However, how these variables interact to influence performance is still understudied. It is in this context that our work, focusing on the individual level, analyzes the moderating effect of commitment on the job crafting-quality of care relationship.

\section{Literature Review}

Recently, several authors found a critical aspect to facilitate quality of care, it is how the employees may be proactive and take initiative redesigning their work (Slemp \& Vella-Brodrick, 2013). These initiatives have been described as job crafting. The concept of job crafting (Wrzesniewski \& Dutton, 2001) was developed as a kind of employees' response to the demands of the workplace. According to these authors, employees are not passive subjects but can influence in their workplace. Hence the concept of job crafting focuses on the redesign of work experience, and the processes by which employees change elements of their jobs. In this sense, the individuals have latitude to define and enact the job, acting as “job crafters” (Tims, Bakker, \& Derks, 2015).

Job crafting concept includes three dimensions (Wrzesniewski \& Dutton, 2001): 1) the scope or number of tasks that occur (task crafting); 2) relations with other people, and exercising discretion about whom one interacts with at work (for instance, making friends with people with similar skills or interests) (relational crafting); 3 ) the modification of the meaning of work and social environment (cognitive crafting).

Against Wrzesniewski and Dutton (2001), Tims and Bakker (2010) conceptualized job crafting within the job-demands model, developing the job demands-resources job crafting model. Under this perspective, el job crafting it's a kind of proactive behavior defined as the changes that employees make in "their levels of job demands and job resources in order to align them with their own abilities and preferences" (Tims \& Bakker, 2010: p. 4). The model establishes three dimensions relatives to three types of job crafting behaviors: 1) increasing job crafting resources, 2) increasing challenging job demands, 3) decreasing 
hindering job demands.

As point out by Lichtenthaler and Fischbach (2016)

The job demands-resources job crafting model seems very useful because it defines three generic job crafting types, which apply to a wide range of job and occupations, and implies that job crating should be facilitated by management to enhance employee motivation (i.e., increases in work engagement) and heath (i.e., decrease in burnout) that subsequently facilitate positive work outcomes for both, employees (e.g. job satisfaction) and organizations (e.g. work performance) (p.4).

Nevertheless, their meta-analysis based on articles published between the years 2000-2015 concludes that "the job demands-resources job crafting model has theoretical shortcomings regarding the crafting of challenging and hindering job demands that are reflected in empirical inconsistencies" (Lichtenthaler \& Fischbach, 2016: p. 4).

It is for this reason that our research is based on the conceptualization described by Wrzesniewski and Dutton (2001). Empirical evidence from this perspective shows job crafting has a positive effect on performance and quality of care in health centers (Tims et al., 2015; Yepes-Baldó et al., 2018). The relationship between job crafting and performance, in the present study, quality of care, may be higher or lower depending on third variables (Wrzesniewski \& Dutton, 2001). One of these third variables could be organizational commitment.

Recently, commitment has been studied as a moderator on different relationships: incivility and well-being (Kabat-Farr, Cortina, \& Marchiondo, 2018), job-demands and well-being (Rivkin, Diestel, \& Schmidt, 2015), transformational leadership and psychological strain (Franke \& Felfe, 2011), stress and performance (Jamal, 2011), work stressors and job satisfaction (Lu, Siu, \& Lu, 2010). In general terms, commitment acted as a protector on negative relations. Reversely, in the present research we propose that commitment and job crafting could interact to facilitate quality of care.

Nevertheless, the relation between job crafting and commitment has not been clearly stablished (Cheng, Chen, Teng, \& Yen, 2016). Some empirical studies have found positive relations among job crafting and commitment (Ghitulescu, 2007), while Leana, Appelbaum, and Shevchuk (2009) found some inconsistencies in this relation. Specifically, Cheng et al. (2016) confirmed a positive relationship between job crafting (individual and collaborative) and commitment, while Leana et al. (2009) found that collaborative job crafting was a predictor of commitment among teachers, but individual job crafting had no effect on it. Contrarily, Ghitulescu (2007) founded a positive relationship between individual cognitive job crafting and commitment among manufacturing employees and teachers.

In the present study, organizational commitment is defined as "the psychological link that employees develop towards the organization” (Romeo, Yepes-Baldó, Berger, Guàrdia, \& Castro, 2011: p. 903). The authors analyzed the psychometric 
properties for organizational commitment, and confirmed four theoretical dimensions: values, affective, exchange and need commitment. Following Romeo et al. (2011), values commitment involves the recognition and consensus of common goals between those of the employee and the organization; affective commitment refers to the affective bond between employee and organization; exchange commitment consists the level of satisfaction related to the retributions/compensations received from the organization; and finally, need commitment implies maintaining the job, as a medium of continuance and survival.

Value, affective and exchange commitment are closely linked to the three components developed by Meyer and Allen (1991): affective, continuance and normative commitment. High levels in all of them, reflect employees' engagement to the organization and their willingness to maintain membership (Meyer, 2016). However, high levels of need commitment are associated with "the most fragile link, if the employee finds employment in another company, he would immediately abandon the current one" (Quijano, 2006: p. 164).

Summing up, employees' job crafting and commitment contribute to the quality of care they give to patients. However, to know how these variables interact to influence performance, specifically increasing the quality of care in eldercare settings, is important but still understudied.

\section{Study Aim}

This study is part of a broader research project aimed at the analysis of the job environment of eldercare and nursing homes employees. In this context, the aim of the present research is to analyze the direct effect of job crafting, specifically, task, relational and cognitive crafting, on quality of care, and the moderator effect of commitment on these relationships. A previous study (Yepes-Baldó et al, 2018) confirmed the direct relationship between job crafting, as an aggregated index, and quality of care. Nevertheless, following the tree-dimensional theoretical structure of job crafting (Wrzesniewski \& Dutton, 2001), on the present research we analyze the differential effect of each dimension on quality of care.

From the preceding literature review, we propose the following hypotheses:

Hypothesis 1: Increased levels of job crafting generate increased levels of quality of care. Specifically:

Increased levels of task crafting (H1.a), relational crafting (H1.b), and cognitive crafting (H1.c) generate increased levels of quality of care.

Additionally, this study aims to analyze the relationship between nursing home employees' job crafting activities and quality of care, moderated by employees' commitment. Therefore, our research tried to verify if value, affective and exchange commitment positively interacts with job crafting to moderate its effect on quality of care, and if need commitment interacts negatively in this relationship. In this regard:

Hypothesis 2: Commitment moderates the relationship between job crafting and quality of care. Specifically: 
Increased levels of quality of care predicted by increased levels of job crafting (cognitive, task and relational) will be only registered in presence of high levels of value commitment (H2.a), affective commitment (H2.b), and exchange commitment (H2.c), and reduced levels of need commitment (H2.d).

Figure 1 illustrates the overall conceptual model and hypotheses.

\section{Method}

\subsection{Design and Participants}

A non-probabilistic accidental sampling was used, because it is considered as practical (speedy, easy, readily available) and cost effective (Henry, 1990). Accidental sampling is a type of non-probability sampling, which doesn't include random selection of participants. Participants are selected not for their representativeness but for their accessibility or handiness (Henry, 1990).

A total of 530 eldercare and nursing homes employees $($ Sweden $=177$; Spain $=$ 353) participated in the present study. The response rate was $78.17 \%(530 / 678)$. Participant mean age was $44.48(\mathrm{SD}=11.77), 87.2 \%$ were female, and $80 \%$ had permanent employment.

\subsection{Ethical Considerations and Data Collection}

Following the approval of the managers and research ethics committees of the participating centers, in Spain, and the regional ethics committee in the Swedish sample, the questionnaires were distributed. As an informed consent, all participants received a letter explaining the procedure and objectives of the research, ensuring the confidentiality of their data and anonymity, as well as their right to leave the study at any time without negative consequences for them.

\subsection{Instruments}

Standardized instruments were used to assess job crafting, quality of care and

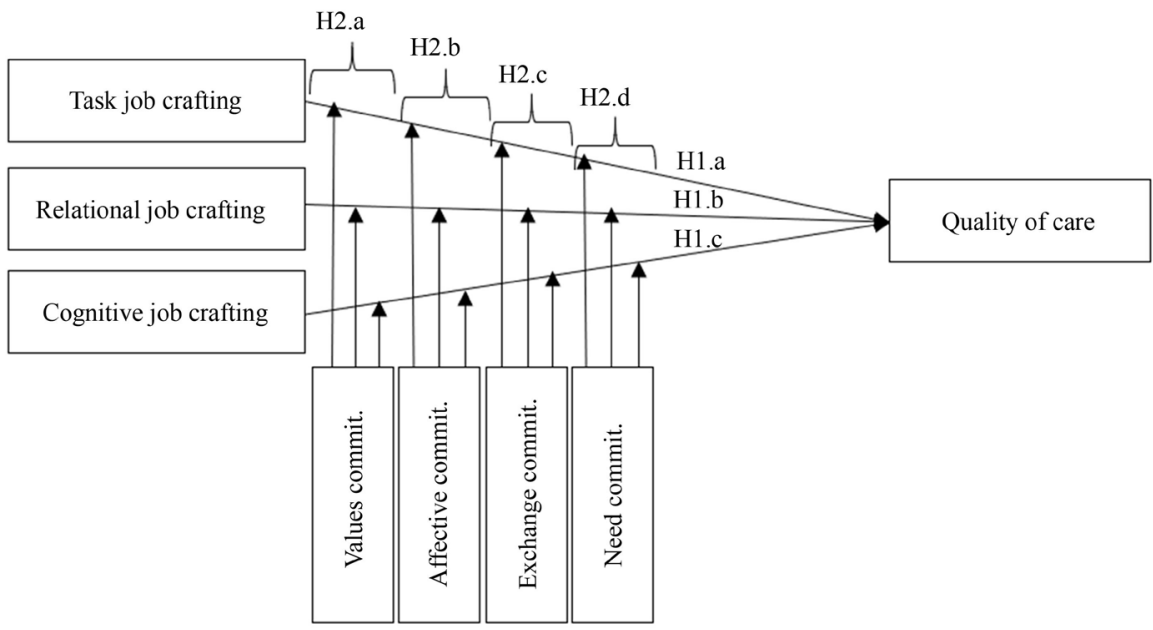

Figure 1. Conceptual model and hypotheses of impact of job crafting on quality of care: the moderating effect of commitment. 
commitment. The original scales were translated and back-translated to Spanish and Swedish following the guidelines of the International Test Commission (2005). Additionally, the questionnaire included sociodemographic data related to age, gender, and contract (permanent or temporary).

Job Crafting Questionnaire (JCQ) (Slemp \& Vella-Brodrick, 2013). This scale is a 15-item instrument with three dimensions: tasks job crafting (TJC) (5 items, e.g., How often do you change the scope or types of tasks that you complete at work?), relational job crafting (RJC) (5 items, e.g., How often do you make friends with people at work who have similar skills or interests?) and cognitive job crafting (CJC) (5 items, e.g., How often do you remind yourself of the importance of your work for the broader community?). The questionnaire is a 6-point Likert-type scale that ranges from 1 (hardly ever) to 6 (very often). All fit indexes supported the three-factor model $(\mathrm{NNFI}=.95 ; \mathrm{IFI}=.96$; $\mathrm{CFI}=.96$; RMSEA $=.06[.05, .08])$ and the internal consistency of the global scale (Slemp \& Vella-Brodrick, 2013).

Quality of Care Questionnaire (QoC) (Westerberg \& Tafvelin, 2014). This scale was used to analyze eldercare and nursing homes employees' perceptions about the centrality of care receivers and the attention they receive. It is a 5-item instrument (e.g., At my workplace, I feel that opinions and wishes of the users/clients receive enough consideration) in a 5-point Likert-type scale that ranges from 1 (Strongly disagree) to 5 (Strongly agree). The internal consistency of the scale was .86 (Westerberg \& Tafvelin, 2014).

Identification-Commitment Inventory (ICI) (Romeo et al., 2011). We used the ICI sub-scale that evaluates employees' commitment. This sub-scale is a 12-item instrument with four dimensions: values commitment (e. g. I feel that there is a big similarity between my personal values and those of this organization), affective commitment (e. g. I feel emotionally linked to this company), exchange commitment (e.g. I continue working in this company as the benefits it provides me are equivalent to the level of effort and dedication that my job requires), and need commitment (e. g. I don't like how this organization functions, I will go to a better one as soon as I can). The inventory is a 5-points Likert-scale ranging from 1 (Strongly disagree) to 5 (Strongly agree). All fit indexes supported the four-factor model (RMSEA $=.029$; RMR $=.049$; GFI = .98; AGFI $=.972$; CFI $=.994)$ and the internal consistency of the global scale (Romeo et al., 2011).

\subsection{Data Analysis}

Data analysis was performed using SPSS 21 with the row data as input. We examined correlation matrices and regression analyses to test bivariate relationships across variables used in the research. Control variables, age, gender, and contract (permanent or temporary), were entered in the first step of the regression, and quality of care in the second. Finally, Hayes' PROCESS macro (Hayes, Montoya, \& Rockwood, 2017) was used to test the moderated models. 


\section{Results}

\subsection{Descriptive Statistics}

Descriptive statistics for the major study variables are presented in Table 1. Cronbach's alphas for the key variables ranged from .65 to .85 , indicating good reliability for each scale. The participants performed moderate job crafting activities, primarily cognitive job crafting $(M=3.29)$. They also reported medium-high ( $M$ = 3.94) levels of perception of quality of care, affective $(M=3.62)$, and values commitment $(M=3.55)$. Finally, levels of need $(M=2.57)$ and exchange commitment $(M=2.93)$ were medium-low.

As presented in Table 1, the job crafting subdimensions correlated significatively $(p<.01)$ with quality of care (CJC: $\mathrm{r}=.279$; RJC: $\mathrm{r}=.202$; TJC: $\mathrm{r}=.194)$. Job crafting and quality of care were also associated with commitment, with correlations ranging from -.47 (need commitment-QoC) to .482 (affective commitment-CJC) $(p<.01)$. The signs of the relationships were negative for need commitment and positive for the rest of the analyzed variables, as expected.

\subsection{Direct Effect of Job Crafting on Quality of Care}

Firstly, we conducted linear regression analyses to test hypotheses H1.a (Increased levels of task crafting generates increased levels of quality of care), H1.b (Increased levels of relational crafting generates increased levels of quality of care), and H1.c (Increased levels of cognitive crafting generates increased levels of quality of care).

Results revealed the direct effect of job crafting dimensions on quality of care (Table 2). Even though all kinds of job crafting explain at least $15.7 \%$ of variance of quality of care, cognitive job crafting is the most related variable, with an explained variance of $27.9 \%$. These findings provide support for Hypothesis 1.a, 1.b, and 1.c. Control variables, age, gender, and contract (permanent or temporary), had not a significant effect.

Table 1. Means, standard deviations, and correlations of variables $(n=530)$.

\begin{tabular}{|c|c|c|c|c|c|c|c|c|c|c|}
\hline Variable & $\mathbf{M}$ & $\mathrm{SD}$ & 1.1 & 1.2 . & 1.3 & 2 & 3.1 & 3.2 & 3.3 & 3.4 \\
\hline \multicolumn{11}{|l|}{ 1. Job crafting } \\
\hline 1.1. Cognitive & 3.29 & .86 & $(.70)$ & & & & & & & \\
\hline 1.2. Task & 3.11 & .82 & $.458^{\star *}$ & $(.78)$ & & & & & & \\
\hline 1.3. Relational & 3.09 & .81 & $.395^{\star *}$ & $.420^{* *}$ & $(.82)$ & & & & & \\
\hline 2. Quality of Care & 3.94 & .67 & $.279^{\star *}$ & $.194^{\star *}$ & $.202^{\star *}$ & $(.82)$ & & & & \\
\hline \multicolumn{11}{|l|}{ 3. Commitment } \\
\hline 3.1. Need & 2.57 & .94 & $-.26^{* *}$ & -.087 & -.079 & $-.47^{\star *}$ & $(.69)$ & & & \\
\hline 3.2. Exchange & 2.93 & .89 & $.316^{* *}$ & $.143^{* *}$ & $.129^{*}$ & $.36^{* *}$ & $-.44^{\star *}$ & $(.65)$ & & \\
\hline 3.3. Affective & 3.62 & .80 & $.482^{* *}$ & $.258^{\star *}$ & $.207^{\star *}$ & $.362^{* *}$ & $-.46^{\star *}$ & $.472^{* *}$ & $(.69)$ & \\
\hline 3.4. Values & 3.55 & .81 & $.364^{\star \star}$ & $.267^{\star *}$ & $.21^{\star \star}$ & $.453^{\star *}$ & $-.50^{\star *}$ & $.482^{\star *}$ & $.709^{\star *}$ & $(.77)$ \\
\hline
\end{tabular}

Scale reliability in the diagonal (In parenthesis); M, Mean; SD, Standard Deviation; ${ }^{* *} p<.001 ;{ }^{*} p<.01$. 
Table 2. Linear regression $(n=530)$.

\begin{tabular}{ccccc}
\hline & \multicolumn{5}{c}{ Quality of care } \\
\hline Variable & Non-standardized b & $\mathrm{R}$ & $\mathrm{R}^{2}$ & $\mathrm{~F}$ \\
\hline 1. Job crafting & & & & \\
1.1. Cognitive & $.214^{* *}$ & .279 & .078 & 44.178 \\
1.2. Task & $.165^{* *}$ & .202 & .038 & 22.217 \\
1.3. Relational & $.157^{* *}$ & .194 & .039 & 20.246 \\
\hline
\end{tabular}

${ }^{* *} p<.001$

\subsection{Moderating Role of Commitment on the Job Crafting-Quality of Care Relationship}

Once we confirmed the direct effect, we analyzed the moderation effect of commitment dimensions. As explained before, we expected that increased levels of quality of care predicted by increased levels of job crafting (cognitive, task and relational) will be only registered in presence of high levels of value commitment (H2.a), affective commitment (H2.b), exchange commitment (H2.c), and reduced levels of need commitment (H2.d) (Table 3). Results showed a moderated effect on the relationship between cognitive job crafting (CJC) and quality of care (QoC), but not on the relationship of task (TJC) and relational job crafting (RJC) and QoC.

Specifically, exchange ( $\mathrm{b} 3=.1067, p=.0006)$, values $(\mathrm{b} 3=.0945, p=.0021)$, and affective commitment $(\mathrm{b} 3=.0882, p=.0069)$ had a moderating effect on the direct relationship CJC-QoC. Nevertheless, results did not confirm the interaction effect of need commitment ( $\mathrm{b} 3=-.040, p=.1627)$ (H2.d).

The direct conditional effects of CJC on QoC at the high and low levels of the moderators are displayed in Table 4.

The direct effect of CJC on QoC was significant when levels of exchange, values, and affective commitment were high, but not when they were low (Figure 2 ). These results mean that only employees with high levels of exchange, affective and values commitment take advantage of doing cognitive job crafting and increase their quality of care. These results confirm hypotheses 2.a, 2.b and 2.c.

\section{Discussion}

Several studies show evidence supporting the relationship between job crafting, performance and quality of care (Yepes-Baldó et al., 2018; Tims et al., 2015; Berg, Dutton, \& Wrzeniewski, 2013). The present research adds to previous studies the moderated effect of employees' commitment on the relationship between nursing home employees' job crafting activities and quality of care.

Specifically, the effect of values, affective, and exchange commitment on the relationship between cognitive job crafting and quality of care was confirmed. In this sense, it is important to note that quality of care depends on the meaning of work (cognitive job crafting) only among nurses within high levels of commitment 

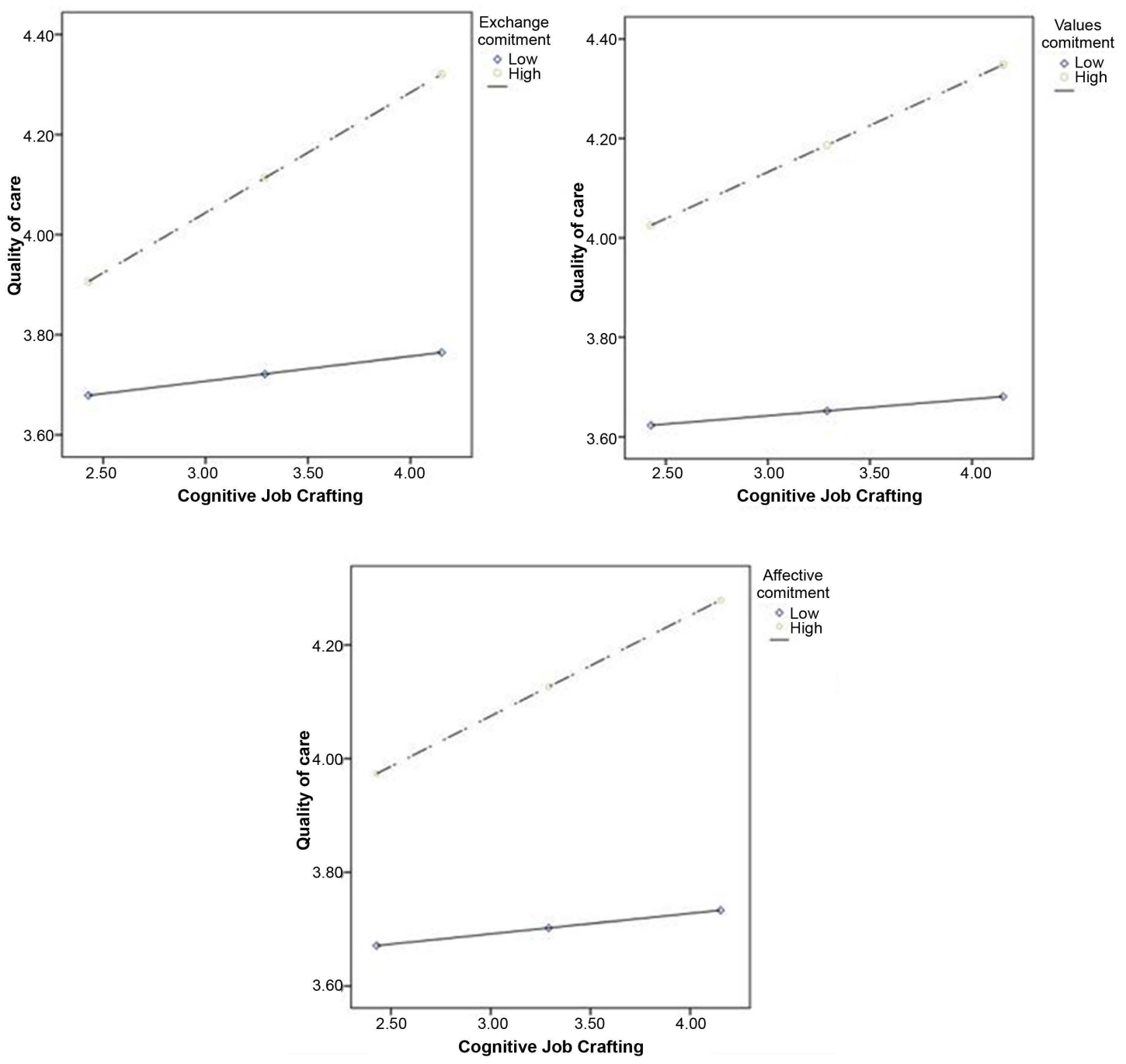

Figure 2. Moderation of exchange, values, and affective commitment on the cognitive job crafting-quality of care relationship.

Table 3. Results of testing the moderation of commitment dimensions on the job crafting-quality of care relationship (interaction effects).

\begin{tabular}{ccccc}
\hline Moderator & Direct relationship & $\mathbf{b}_{\mathbf{3}}$ & $\mathrm{SE}$ & $\mathbf{t}$ \\
\hline \multirow{3}{*}{ Need commitment } & CJC-QoC & -.0404 & .0289 & -1.3981 \\
& TJC-QoC & -.0064 & .0312 & -.2038 \\
& RJC-QoC & -.0622 & .0310 & -2.0057 \\
\multirow{3}{*}{ Exchange commitment } & CJC-QoC & $.1067^{* *}$ & .0308 & $3.4626^{* *}$ \\
& TJC-QoC & -.0017 & .0349 & -.0479 \\
& RJC-QoC & .0176 & .0356 & .4949 \\
\multirow{3}{*}{ Affective commitment } & CJC-QoC & $.0882^{\star}$ & .0325 & $2.7120^{*}$ \\
& TJC-QoC & .0288 & .0384 & .7505 \\
& RJC-QoC & .0554 & .0403 & 1.3737 \\
Values commitment & CJC-QoC & $.0945^{\star}$ & .0305 & $3.0972^{\star}$ \\
& TJC-QoC & .0662 & .0335 & 1.9720 \\
& RJC-QoC & .0752 & .0364 & 2.0623 \\
\hline
\end{tabular}

$\mathrm{SE}$, standard error; ${ }^{* *} p<.001 ;{ }^{*} p<.01$. 
Table 4. Results of testing the moderation of low and high levels of commitment on the cognitive job crafting-quality of care relationship.

\begin{tabular}{cccccc}
\hline \multirow{2}{*}{ Variable } & Level & $\begin{array}{c}\text { Direct } \\
\text { conditional effect }\end{array}$ & Boot SE & \multicolumn{2}{c}{ 95\% CI } \\
\cline { 5 - 6 } $\begin{array}{c}\text { Exchange } \\
\text { commitment }\end{array}$ & $\begin{array}{c}\text { Low } \\
\text { (Mean - 1 SD) }\end{array}$ & .0498 & .0416 & -.0318 & .1315 \\
& High (Mean + 1 SD) & .243 & .0432 & .1555 & .3252 \\
$\begin{array}{c}\text { Values } \\
\text { commitment }\end{array}$ & $\begin{array}{c}\text { Low } \\
\text { (Mean - 1 SD) }\end{array}$ & .0336 & .0387 & -.0424 & .1096 \\
& High (Mean + 1 SD) & .1871 & .042 & .1046 & .2695 \\
$\begin{array}{c}\text { Affective } \\
\text { commitment }\end{array}$ & $\begin{array}{c}\text { Low } \\
(\text { Mean }-1 \text { SD) }\end{array}$ & .0361 & .0431 & -.0486 & .1208 \\
& High (Mean + 1 SD) & .1771 & .0446 & .0895 & .2648 \\
\hline
\end{tabular}

SD, standard deviation; SE, standard error; CI, confidence interval; LL, lower limit; UL, upper limit. Bootstrap sample size $=10,000$.

with their organization. Contrarily, among nurses with low levels of commitment, the quality of care is independent of their cognitive job crafting activities.

Another interesting result is that nurses that perceive they are working in their organization exclusively because they need to survive (need commitment), perceived low levels of quality of care, independently of their job crafting activities. In this sense, job crafting activities do not interact with this kind of commitment to palliate this negative situation.

Nurses that modify the way they perform their work or include tasks more related to their needs and abilities (task job crafting), and those that have positive personal relations with their co-workers (relations job crafting) perceive higher levels of quality of care, not moderated by the levels of commitment they have.

This research contributes to the understanding of the interactions among job crafting and commitment to explain the quality of care in eldercare settings. This analysis represents the novelty of the present research, adding explanatory power to the direct effect of job crafting on quality of care, confirmed in a previous study (Yepes-Baldó, Romeo, Westerberg, \& Nordin, 2018).

\section{Limitations and Future Research}

The present study has some limitations to consider. First, the use of a non-probabilistic accidental sampling and the context were data was collected (eldercare and nursing homes), raise questions about the generalizability of our findings to the general nursing population. Future research should replicate our study among larger samples and on different healthcare contexts and countries.

Secondly, the study is based entirely on self-reported measures. Specifically, the quality of care variable was measured by the nurses' perceptions. Even though other recent studies have used nurses' perceptions of nurses as measures of performance (i.e. Geyer, Coetzee, Ellis, \& Uys, 2018) it could generate social desira- 
bility response bias. Stronger evidence should be obtained from objective measures of quality of service and perceived quality of care by care receivers in future research.

Finally, our research had a correlational cross-sectional design. For this reason, causality relations may be more firmly established in a longitudinal or experimental study. Additionally, future research should analyze the effect of interventions to enhance employees' job crafting activities on different performance indicators, including quality of care.

\section{Conclusion}

The results of this study highlight the importance of nurses' job crafting activities, especially cognitive job crafting, for quality of care. On the other hand, it is important to note the effect of commitment, as an antecedent of quality of care, and as a moderator of the relationship between job crafting and quality of care. In this sense, managers should guarantee psychological contract fulfillment, which has been related to increased levels of commitment and decreased levels of intention to quit (Rodwell \& Ellershaw, 2016).

\section{Acknowledgements}

This project was funded by the Swedish Research Council for Health, Working Life and Welfare (FORTE), Dnr 2015-00708.

\section{Conflicts of Interest}

The authors declare no conflicts of interest regarding the publication of this paper.

\section{References}

Berg, J. M., Dutton, J. E., \& Wrzesniewski, A. (2013). Job Crafting and Meaningful Work. In B. J. Dik, Z. S. Byrne, \& M. F. Steger (Eds.), Purpose and Meaning in the Workplace (pp. 81-104). Washington DC: American Psychological Association. https://doi.org/10.1037/14183-005

Cheng, J. C., Chen, C. Y., Teng, H. Y., \& Yen, C. H. (2016). Tour Leaders' Job Crafting and Job Outcomes: The Moderating Role of Perceived Organizational Support. Tourism Management Perspectives, 20, 19-29. https://doi.org/10.1016/j.tmp.2016.06.001

European Commission (2017). Blueprint Digital Transformation of Health and Care for the Ageing Society. Brussels: EC. http://ec.europa.eu/newsroom/document.cfm?doc id=40787

Franke, F., \& Felfe, J. (2011). How Does Transformational Leadership Impact Employees' Psychological Strain? Examining Differentiated Effects and the Moderating Role of Affective Organizational Commitment. Leadership, 7, 295-316. https://doi.org/10.1177/1742715011407387

Geyer, N. M., Coetzee, S. K., Ellis, S. M., \& Uys, L. R. (2018). Relationship of Nurses' intrapersonal Characteristics with Work Performance and Caring Behaviors: A Cross-Sectional Study. Nursing \& Health Sciences, 20, 1-8.

https://doi.org/10.1111/nhs.12416 
Ghitulescu, B. E. (2007). Shaping Tasks and Relationships at Work: Examining the Antecedents and Consequences of Employee Job Crafting. Doctoral Dissertation, Ewing: The College of New Jersey. http://d-scholarship.pitt.edu/10312/1/ghitulescube_etd.pdf

Hayes, A. F., Montoya, A. K., \& Rockwood, N. J. (2017). The Analysis of Mechanisms and Their Contingencies: PROCESS versus Structural Equation Modeling. Australasian Marketing Journal, 25, 76-81. https://doi.org/10.1016/j.ausmj.2017.02.001

Henry, G. T. (1990). Practical Sampling (10th ed.). Newbury Park: Sage Publications. https://doi.org/10.4135/9781412985451

International Test Commission (2005). ITC Guidelines for Translating and Adapting Tests. Document Reference: ITC-G-TA-20140617. http://www.intestcom.org/files/guideline_test_adaptation.pdf

Jamal, M. (2011). Job Stress, Job Performance and Organizational Commitment in a Multinational Company: An Empirical Study in Two Countries. International Journal of Business and Social Science, 2, 20-29.

Kabat-Farr, D., Cortina, L. M., \& Marchiondo, L. A. (2018). The Emotional Aftermath of Incivility: Anger, Guilt, and the Role of Organizational Commitment. International Journal of Stress Management, 25, 109-128. https://doi.org/10.1037/str0000045

Leana, C., Appelbaum, E., \& Shevchuk, I. (2009). Work Process and Quality of Care in Early Childhood Education: The Role of Job Crafting. Academy of Management Journal, 52, 1169-1192. https://doi.org/10.5465/amj.2009.47084651

Lichtenthaler, P. W., \& Fischbach, A. (2016). Promotion- and Prevention-Focused Job Crafting: A Theoretical Extension and Meta-Analytical Test. Academy of Management Proceedings, 2016, Article Id: 10818. https://doi.org/10.5465/ambpp.2016.10818abstract

Lu, L., Siu, O. L., \& Lu, C. Q. (2010). Does Loyalty Protect Chinese Workers from Stress? The Role of Affective Organizational Commitment in the Greater China Region. Stress and Health, 26, 161-168. https://doi.org/10.1002/smi.1286

Meyer, J. P. (Ed.) (2016). Handbook of Employee Commitment. Cheltenham, UK: Edward Elgar Publishing. https://doi.org/10.4337/9781784711740

Meyer, J. P., \& Allen, N. J. (1991). A Three-Component Conceptualization of Organizational Commitment. Human Resource Management Review, 1, 61-89. https://doi.org/10.1016/1053-4822(91)90011-Z

Quijano, S. (2006). Human Resources Management and Organizational Audits: The HSA (Human System Audit). Barcelona: Icaria Editorial.

Rivkin, W., Diestel, S., \& Schmidt, K. H. (2015). Affective Commitment as a Moderator of the Adverse Relationships between Day-Specific Self-Control Demands and Psychological Well-Being. Journal of Vocational Behavior, 88, 185-194. https://doi.org/10.1016/j.jvb.2015.03.005

Rodwell, J., \& Ellershaw, J. (2016). Fulfill Promises and Avoid Breaches to Retain Satisfied, Committed Nurses. Journal of Nursing Scholarship, 48, 406-413. https://doi.org/10.1111/jnu.12215

Romeo, M., Yepes-Baldó, M., Berger, R., Guàrdia, J., \& Castro, C. (2011). Identification Commitment Inventory (ICI Model): Confirmatory Factor Analysis and Construct Validity. Quality \& Quantity, 45, 901-909. https://doi.org/10.1007/s11135-010-9402-0

Shin, J. I., \& Lee, E. (2016). The Effect of Social Capital on Job Satisfaction and Quality of Care among Hospital Nurses in South Korea. Journal of Nursing Management, 24, 934-942. https://doi.org/10.1111/jonm.12401

Slemp, G. R., \& Vella-Brodrick, D. A. (2013). The Job Crafting Questionnaire: A New 
Scale to Measure the Extent to Which Employees Engage in Job Crafting. International Journal of Wellbeing, 3, 126-146.

Tims, M., \& Bakker, A. B. (2010). Job Crafting: Towards a New Model of Individual Job Redesign. South African Journal of Industrial Psychology, 36, 1-9. https://doi.org/10.4102/sajip.v36i2.841

Tims, M., Bakker, A. B., \& Derks, D. (2015). Job Crafting and Job Performance: A Longitudinal Study. European Journal of Work and Organizational Psychology, 24, 914-928. https://doi.org/10.1080/1359432X.2014.969245

Van Bogaert, P., Kowalski, C., Weeks, S. M., \& Clarke, S. P. (2013). The Relationship between Nurse Practice Environment, Nurse Work Characteristics, Burnout and Job Outcome and Quality of Nursing Care: A Cross-Sectional Survey. International Journal of Nursing Studies, 50, 1667-1677. https://doi.org/10.1016/j.ijnurstu.2013.05.010

Westerberg, K., \& Tafvelin, S. (2014). The importance of leadership style and psychosocial work environment to staff-assessed quality of care: Implications for home help services. Health and Social Care in the Community, 22, 461-468.

Wrzesniewski, A., \& Dutton, J. E. (2001). Crafting a Job: Revisioning Employees as Active Crafters of Their Work. Academy of Management Review, 26, 179-201.

https://doi.org/10.1111/hsc.12084

Yepes-Baldó, M., Romeo, M., Westerberg, K., \& Nordin, M. (2018). Job Crafting, Employee Well-Being, and Quality of Care. Western Journal of Nursing Research, 40, 52-66. https://doi.org/10.1177/0193945916680614 